than most efforts to bridge the gap between neurophysiology and behaviour-in this case, emotion.

All the leading papers are provocative. The opening thesis by Pribram offers a fascinating definition in neurophysiological terms of emotion. It is clear from the discussions which follow that not all the psychologists participating in the conference agreed, nor is it likely that other psychologists reading this book will agree either. Pribram's thesis, separating "preparatory" processes and "participatory" processes, is supported by a considerable body of neurophysiological evidence. Much of it, although it cannot be regarded as full and final proof of his theory, at least offers a very reasonable working hypothesis. It is clear, however, from the discussions which are reproduced in the rest of the book, that there was failure to reach agreement between the physiologists and the psychologists on an adequate definition of emotion.

How this gap can be closed is still a matter for further debate. Too much of the psychological approach takes scant notice of the basic neurophysiology. Too much of the physiologists' approach is content with rather superficial correlation between some aspect of "behaviour" and a physical finding. This is evideneed in the extremely interesting work of Brady, who presents many interesting facts in respect of catecholamine and corticosteroid levels during various changes in behaviour. Much of this is correlated, but how much of it is actually cause and effect? The contribution by the late D. Wayne Wooley is tantalizingly incomplete-its brief reference to the role of a ganglioside as the 5-hydroxytryptamine receptor and the possibility of a ganglioside as a synergist for 5 hydroxytryptamine is undue modesty.

By far the most thoughtful of the contributions of the psychologists is that of Stanley Schachter. His report on the eating habits of the obese are interpreted in terms of the environmental cues that identify hunger. But again, could these findings not also have been interpreted in terms of physiopathology, as the author admits, although he does not expound? Several contributors reiterate the need to abandon any simple stimulus response pattern concept in our attempt to understand behaviour and draw attention to the noed to direct research energies towards the complete description of the organism in the environment.

The final section on infantile stimulation throws considerable doubt on the background stability of any emotional reaction in the adult, as it is clear from V. H. Denenberg's report that many experiences during different stages of ontogeny affect "physiological" characteristics in adulthood.

The references are extensive and valuable. One minor mistake seems to be the omission of the list of conference participants which, on page 6 of the introduction, we are promised will be given at the end of the volume.

Nevertheless, the volume is an extremely valuable record of a most interesting, useful conference, even though limited in its scope and even if it only pinpoints the continuing difficulty of finding an adequate definition for "emotion".

J. L. MaLcolm

\section{BIOLOGY FILM STRIPS}

\section{Film Strips}

No. FC 3004, The Bumble Bee, 36s. No. FC 0117, The Silk Worm, 36s. No. FC 3003, The Honey Bee, 36s. No. 6550, Mitosis, 30s. No. C6676, Pond Life, 30s. No. C $6675,36 s$. (Educational Productions Limited, Wake. field, Yorkshire) (Plus booklets for each film).

Finm strips tend to fall into two categories: those that are merely a collection of frames related rather haphazardly to some topic and those that provide a connected account of a subject. Vegetative Reproduction and Pond life fall into the first category. The former has thirtysix frames of specimens exhibiting vegetative reproduction. They are mainly angiosperms and include the more common examples, such as potato tubers and iris rhizome. Indeed, most of them are easily obtained and could be shown to pupils at first hand. This would enable important anatomical details to be observed which are obscure in the film strip. The arrangement of the specimens in the frames is sometimes poor. Pond Life consists of an opening frame of a lake to illustrate zonation, but only does so for the water surface and above. Then follow sixteen frames of aquatic plants and nineteen of aquatic animals. The quality of the photographs is variable and two specimens are wrongly identified. Important details are not clear in some frames.

In contrast The Honey Bee (thirty-nine frames) and The Bumble Bee (twenty-one frames) provide coherent and informative accounts of their subjects. Many aspects of the life of the bees both in and out of their colonies are illustrated by clear, dotailed photographs. Each would provide a good focus for an elementary consideration of social insects.

Mitosis also provides a connected account but, unfortunately, one told many times before. The first nine frames show mitotic stages in the root tip of a broad bean $(\times 400)$. The last three frames are of mitotic division in whitefish cells $(\times 200)$ provided to allow the differences between plant and animal cell division to be detected. The photographs are adequate, but their resolution is sometimes poor. Similar photographs are to be found in many books these days; some are available in sots at a cheaper price; and with film loops on the topic freely available it is difficult to see real value in this film strip.

Unlike the others, The Silkworm relies on paintings rather than actual specimens. In twenty-five frames it attempts to demonstrate the use of silk, the life cycle of the silk worm, some aspects of silk production and a brief history of the spread of sericulture from China to Europe. It would be useful material for a potted lecture on sericulture as an aspect of social history but, because of its diversity, it is difficult to see how it could be integrated adequately into a teaching programme.

Those six film strips are in colour. Notes are provided with them which supply descriptions of the frames, a little background information, sometimes a glossary and in the case of Mitosis a short bibliography. They provide no guidance on suitable teaching techniques.

\section{P. J. KELILY}

\section{University News}

Dr H. M. Keir, University of Glasgow, has been appointed to the chair of biological chemistry at the University of Aberdeen on the retirement of Professor W. O. Kermack.

Dr D. Livingstone, University of Michigan, Ann Arbor, has been appointed to the additional chair of pure mathematics in the University of Birmingham, and Professor J. T. Eayrs, Institute of Psychiatry, University of London, has been appointed to the Sands Cox chair of anatomy.

Mr G. R. Nicoll, University of Cambridge, has been appointed to the chair of electrical and electronic engineering at Heriot-Watt University, Edinburgh, on the retirement of Professor E. Openshaw Taylor.

Professor A. Young, University of Liverpool, is to be professor of mathematics in the University of Ulster. 